\title{
DIAGNÓSTICO DA CADEIA PRODUTIVA DE CAPRINOS E OVINOS NO BRASIL
}

\author{
Maicon Gonçalves Monteiro \\ Marlon Vinícius Brisola \\ José Eustáquio Ribeiro Vieira Filho
}

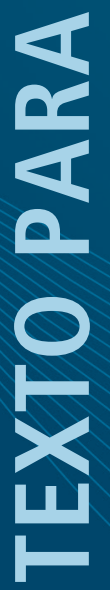

4

2

U

U







\section{TEXTO PARA DISCUSSÃO}

Brasília, junho de 2021

\section{DIAGNÓSTICO DA CADEIA PRODUTIVA DE CAPRINOS E OVINOS NO BRASIL}

Maicon Gonçalves Monteiro'

Marlon Vinícius Brisola²

José Eustáquio Ribeiro Vieira Filho ${ }^{3}$

1. Pesquisador do Núcleo de Estudos de Economia Agrícola na Diretoria de Estudos e Políticas Regionais, Urbanas e Ambientais (Dirur) do Ipea.E-mail: <maicongoncalves675@gmail.com>.

2. Professor do Programa de Pós-graduação em Agronegócios da Universidade de Brasília (Propaga/UnB). E-mail: <mvbrisola@gmail.com>.

3. Técnico de planejamento e pesquisa na Dirur/lpea, diretor de programa na Secretaria Executiva do Ministério da Agricultura, Pecuária e Abastecimento (Mapa), e professor no Propaga/UnB e de Economia na Universidade Federal de Viçosa (UFV).E-mail: <jose.vieira@ipea.gov.br>. 


\section{Governo Federal \\ Ministério da Economia \\ Ministro Paulo Guedes}

 Econômica Aplicada}

Fundação pública vinculada ao Ministério da Economia, o Ipea fornece suporte técnico e institucional às ações governamentais - possibilitando a formulação de inúmeras políticas públicas e programas de desenvolvimento brasileiros - e disponibiliza, para a sociedade, pesquisas e estudos realizados por seus técnicos.

\section{Presidente}

Carlos von Doellinger

Diretor de Desenvolvimento Institucional Manoel Rodrigues Junior

Diretora de Estudos e Políticas do Estado, das Instituições e da Democracia

Flávia de Holanda Schmidt

Diretor de Estudos e Políticas

Macroeconômicas

José Ronaldo de Castro Souza Júnior

Diretor de Estudos e Políticas Regionais, Urbanas e Ambientais

Nilo Luiz Saccaro Júnior

Diretor de Estudos e Políticas Setoriais de Inovação e Infraestrutura

André Tortato Rauen

Diretora de Estudos e Políticas Sociais

Lenita Maria Turchi

Diretor de Estudos e Relações Econômicas

e Políticas Internacionais

Ivan Tiago Machado Oliveira

Assessor-chefe de Imprensa e Comunicação André Reis Diniz

Ouvidoria: http://www.ipea.gov.br/ouvidoria

URL: http://www.ipea.gov.br

\section{Texto para Discussão}

Publicação seriada que divulga resultados de estudos e pesquisas em desenvolvimento pelo Ipea com o objetivo de fomentar o debate e oferecer subsídios à formulação e avaliação de políticas públicas.

(C) Instituto de Pesquisa Econômica Aplicada - ipea 2021

Texto para discussão / Instituto de Pesquisa Econômica Aplicada.- Brasília : Rio de Janeiro : Ipea , 1990-

ISSN 1415-4765

1.Brasil. 2.Aspectos Econômicos. 3.Aspectos Sociais. I. Instituto de Pesquisa Econômica Aplicada.

CDD 330.908

As publicações do Ipea estão disponíveis para download gratuito nos formatos PDF (todas) e EPUB (livros e periódicos).

Acesse: http://www.ipea.gov.br/portal/publicacoes

As opiniões emitidas nesta publicação são de exclusiva e inteira responsabilidade dos autores, não exprimindo, necessariamente, o ponto de vista do Instituto de Pesquisa Econômica Aplicada ou do Ministério da Economia.

É permitida a reprodução deste texto e dos dados nele contidos, desde que citada a fonte. Reproduções para fins comerciais são proibidas.

JEL: 013; Q01; Q18. 


\section{SUMÁRIO}

SINOPSE

ABSTRACT

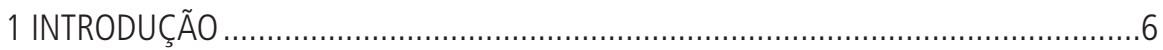

2 EVOLUÇÃO E DISTRIBUIÇÃO DA CAPRINOVINOCULTURA NO BRASIL.....................7

3 CADEIA PRODUTIVA DE CAPRINOS E OVINOS ................................................ 14

4 LIMITAÇÕES E AVANÇOS EVIDENCIADOS NAS CADEIAS PRODUTIVAS

DA CAPRINOVINOCULTURA NO BRASIL .........................................................18

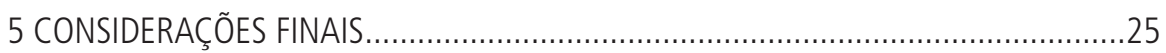

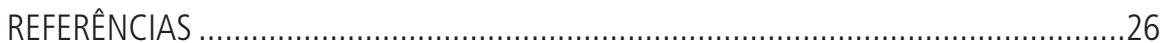





\section{SINOPSE}

O agronegócio brasileiro, setor que representa um quarto da economia do país, passou por significativas transformaçóes desde a década de 1960. Com a abertura econômica e a estabilizaçáo financeira dos anos 1990, diversos segmentos produtivos do agronegócio mantiveram bom desempenho, embora a cadeia de caprinos e ovinos, em particular, enfrentasse dificuldades em sua trajetória. Assim, este estudo, por meio da descrição, buscou realizar um diagnóstico do complexo agroindustrial da caprinovinocultura no Brasil, destacando seus principais limitantes, demandas e avanços. Identificou-se que os principais problemas derivam da informalidade presente no setor, da carência de políticas e açóes privadas que promovam a capacitação dos produtores, do amparo às atividades de produção e da insustentabilidade na comercialização dos produtos derivados a partir de ações integradas entre produtores e entre o público e o privado. Destacaram-se ainda açôes importantes já realizadas no setor, como a Rota do Cordeiro e a formação de cooperativas de produtores.

Palavras-chave: agronegócio; políticas públicas; caprinovinocultura.

\section{ABSTRACT}

Brazilian agribusiness, a sector that represents a quarter of the country's economy, has undergone significant transformations since the 1960s. With the economic opening and financial stabilization of the 1990s, several agribusiness productive segments maintained a good performance, although the supply chain goats and sheep, in particular, faced difficulties in their trajectory. Thus, this study, by means of the description, sought to make a diagnosis of the agro-industrial complex of goat breeding in Brazil, highlighting its main limitations, demands and advances. It was identified that the main problems stem from the informality present in the sector, the lack of private policies and actions that promote the training of producers, the support to production activities and the unsustainability in the commercialization of products derived from integrated actions between producers and between public and private. Important actions already taken in the sector were highlighted, such as the Rota do Cordeiro and the formation of producer cooperatives.

Keywords: agribusiness; public policy; caprinovinoculture. 


\section{INTRODUÇÃO}

O agronegócio brasileiro é um dos principais setores que impulsiona a economia do país, compondo boa parte do produto interno bruto (PIB). O setor passou por significativas transformações desde os anos 1960, alavancado por um ambiente institucional mais favorável à inovação e à adaptaçáo de conhecimento e de tecnologia, bem como pela ampliação dos mercados de exportação (Vieira Filho e Gasques, 2016). Como resultado, obteve importantes aumentos em sua escala de produção, com ganhos em produtividade e sustentabilidade, assim como no grau de complexidade das várias cadeias produtivas (Gasques et al., 2012; Jank, Zerbine e Cleaver, 2018).

Diante de um cenário que se mostrou, em geral, economicamente favorável aos vários setores do agronegócio, diversas cadeias produtivas no Brasil conseguiram se manter ou obter um bom desempenho segundo dados do Fundo Monetário Internacional - FMI (2019). No entanto, a cadeia de caprinos e ovinos enfrentou consideráveis dificuldades em sua trajetória, uma constatação do Ministério da Integração Nacional - MIN (Brasil, 2017), especialmente no que tange às questóes relacionadas às dificuldades enfrentadas pelos pequenos produtores rurais para alcançarem bom desempenho técnico e econômico com a atividade (Sousa Filho e Bonfim, 2013).

Conforme Brisola (2011), levantaram-se os principais problemas da caprinovinocultura nacional, alguns elementos como a desorganização setorial, a informalidade nas transaçôes, a descontinuidade e/ou desqualificação da assistência técnica, o baixo estímulo empreendedor, o despreparo da mão de obra e a pouca integração público-privada foram apontados como mais relevantes ao setor. Em relação à orientação técnica, destacou-se que esta náo era suficiente para o desenvolvimento adequado da atividade (Medeiros et al., 2005).

Por muito tempo, esse segmento produtivo foi colocado a uma posição marginal, quando comparado a outros segmentos produtivos do agronegócio (Ribeiro e Alencar, 2018). Contudo, estudos relacionados às cadeias produtivas locais e regionais vieram a colaborar para a desmistificação de tal indicação, revelando sua importância e notoriedade (Guimarães Filho, Soares e Araújo, 2000; Malafaia, Barcellos e Azevedo, 2006; Guimarães Filho, Silva e Azevedo, 2011; Souza e Barros, 2017). 
Ao longo do tempo, as criaçôes de ovinos e caprinos se desenvolveram de forma gradativa e pontual no território brasileiro, sendo as regióes Sul e Nordeste, respectivamente, as protagonistas das duas espécies. Mudanças ocorreram em suas composiçóes, mas são estas as regióes que concentram ainda o maior efetivo e número de produtores: no Sul estão 21,2\% dos ovinos, enquanto no Nordeste, 93,3\% dos caprinos (IBGE, 2018).

No Brasil, existem diversas raças com aptidóes produtivas, voltadas em maior ou menor grau à produçáo de carne, leite, lá e pele de qualidade, conforme indica a Companhia de Desenvolvimento dos Vales do São Francisco e do Parnaíba - Codevasf (Codevasf, 2011). O desempenho da caprinovinocultura no Brasil varia conforme a região e características dos sistemas de produção, a estabilidade nas relaçôes entre criadores, frigoríficos e distribuidores comerciais, bem como o consequente grau de especificidade dos produtos transacionados (Malafaia, Barcellos e Azevedo, 2006).

Diante desse contexto, considerando um período de trinta anos, este estudo traça uma análise descritiva e um diagnóstico decenal do sistema agroindustrial da caprinovinocultura e de suas cadeias produtivas no Brasil, enfatizando suas características, limitações e avanços do setor.

\section{EVOLUÇÃO E DISTRIBUIÇÃO DA CAPRINOVINOCULTURA NO BRASIL}

O Brasil possui longa tradição na criação de caprinos e ovinos, atividades responsáveis pela sustentação econômica e nutricional de muitas famílias da zona rural, principalmente aquelas de menor renda (Sorio, 2017). Considerando essa importância social, o Brasil viu sua demanda cada vez mais crescente pelos produtos oriundos da caprinovinocultura, firmando-se ainda como notável importador, visto a quantidade de animais e produtos desse setor que entrou no país desde a década de 1990 (Embrapa, 2016).

Nas últimas décadas, a exploração desses animais tornou-se mais favorável, ano após ano, especialmente a partir do ano de 1996 para caprinos, e a partir de 2002 para os ovinos (gráfico 1), superando uma grave crise que o setor enfrentou em anos anteriores. 
GRÁFICO 1

Evolução do rebanho nacional de caprinos e ovinos (1988-2018)

(Em milhões de cabeças)



Caprinos Ovinos

Fonte: FAO (2018).

De forma geral, tanto o crescimento, quanto a redução do rebanho de caprinos e ovinos no país seguiram um ritmo parecido, levando a crer que ambos foram afetados fortemente pelos mesmos fatores que influenciaram o aumento ou não do número de animais.

Claramente, após o rebanho de ovinos ter apresentado um crescimento constante desde 2002, houve uma significativa redução do número de animais em 2012 que, de acordo com a Embrapa (2017), foi devido ao período de seca vigorosa na região Nordeste naquele ano. $\mathrm{O}$ rebanho de caprinos também parece ter sofrido com esse fator negativo em 2012, embora estivesse apresentasse redução desde 2006. Ambos, porém, apresentaram aumento em seu efetivo desde então (FAO, 2018).

Esse crescimento também pode ser observado e comparado com os dados dos Censos Agropecuários de 2006 e 2017. Em 2006 foi computado cerca de 7,1 milhóes de cabeças de caprinos e 14,1 milhões de ovinos (IBGE, 2006). Enquanto em 2017 foram levantados quantitativos de rebanhos de caprinos e ovinos de 8,26 milhôes e 13,7 milhões de cabeças, respectivamente (IBGE, 2017). 
Levando em conta o período entre 1998 e 2018, ou seja, período que decorreu uma crise na demanda de produtos da caprinovinocultura em âmbito mundial, o rebanho de caprinos e ovinos no Brasil computou uma variaçáo positiva de 34,2\% e 30,4\%, respectivamente. (FAO, 2018).

No que se refere aos estados brasileiros com maior número de caprinos e ovinos em 2018, destacam-se, para o rebanho de caprinos, a Bahia - com quase um terço do plantel nacional, um efetivo de 3,2 milhóes de cabeças -, seguida por Pernambuco, Piauí e Ceará (gráfico 2).

\section{GRÁFICO 2}

Estados brasileiros com maiores rebanhos de caprinos

(Em milhões de cabeças)

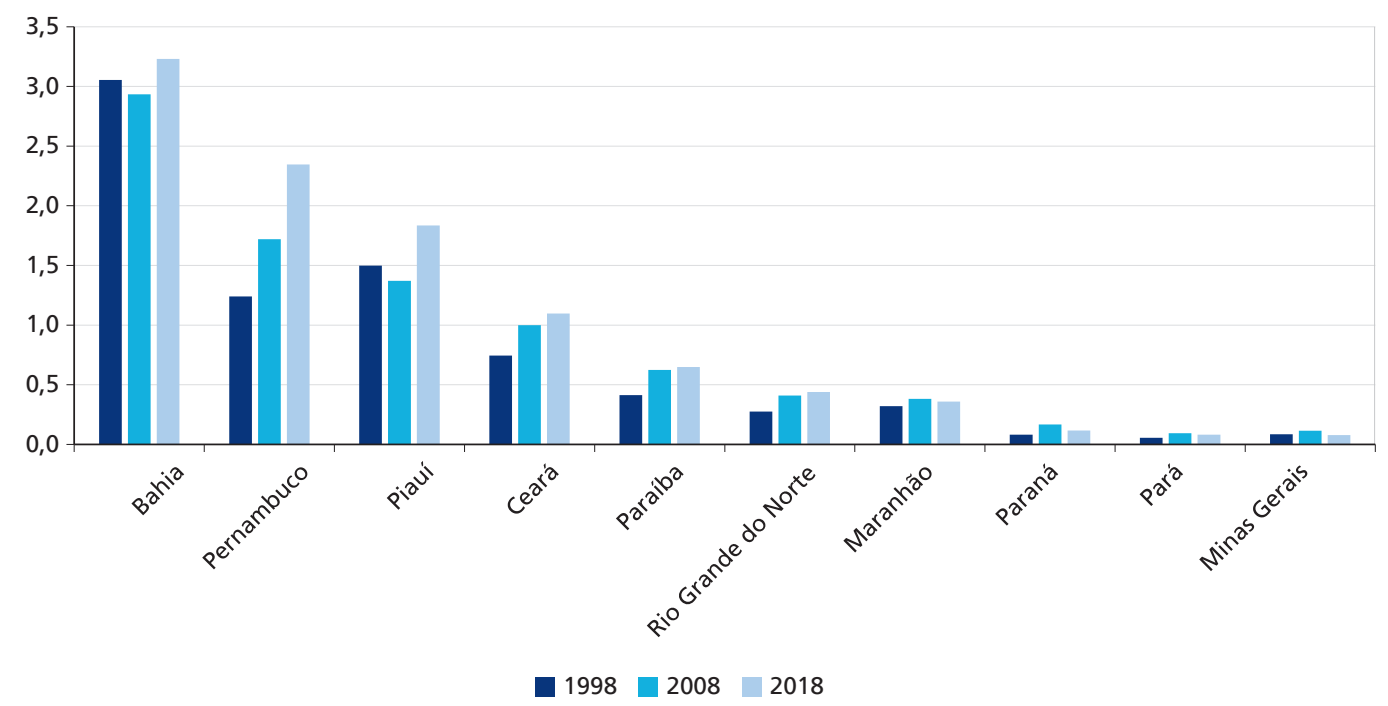

Fonte: IBGE (2018)

Em termos de crescimento, Pernambuco merece destaque, com uma variação crescente de 89,4\% e 36,4\% entre os períodos de 1998 a 2008 e de 2008 a 2018, respectivamente. Trata-se de um estado que demonstra sua grande importância na criação de caprinos através da sua densidade de animais, contabilizando 24 cabeças de caprinos por $\mathrm{km}^{2} \mathrm{em}$ 2018, seguido pela Paraíba, com onze animais $/ \mathrm{km}$. ${ }^{2}$ Seguem, o Piauí e o Ceará com sete cabeças $/ \mathrm{km}^{2}$ e a Bahia com seis cabeças de caprinos por $\mathrm{km}^{2}$ (IBGE, 2019). 
No que tange à criação de ovinos, enquanto os estados do Nordeste mantêm curvas ascendentes em número de animais, os dois principais estados do Sul - Rio Grande do Sul e Paraná - observaram seus rebanhos declinarem, com uma variação negativa de $38 \%$ e $3 \%$, respectivamente, em relação a 1998 , e com $20,5 \%$ e $4 \%$ em relação à 2008, na mesma ordem. A Bahia também se destaca como maior produtor de ovinos em 2018, tomando o posto que antes era do Rio Grande do Sul, com um efetivo de 4,2 milhôes de cabeças (gráfico 3).

GRÁFICO 3

Estados brasileiros com maiores rebanhos de ovinos

(Em milhões de cabeças)

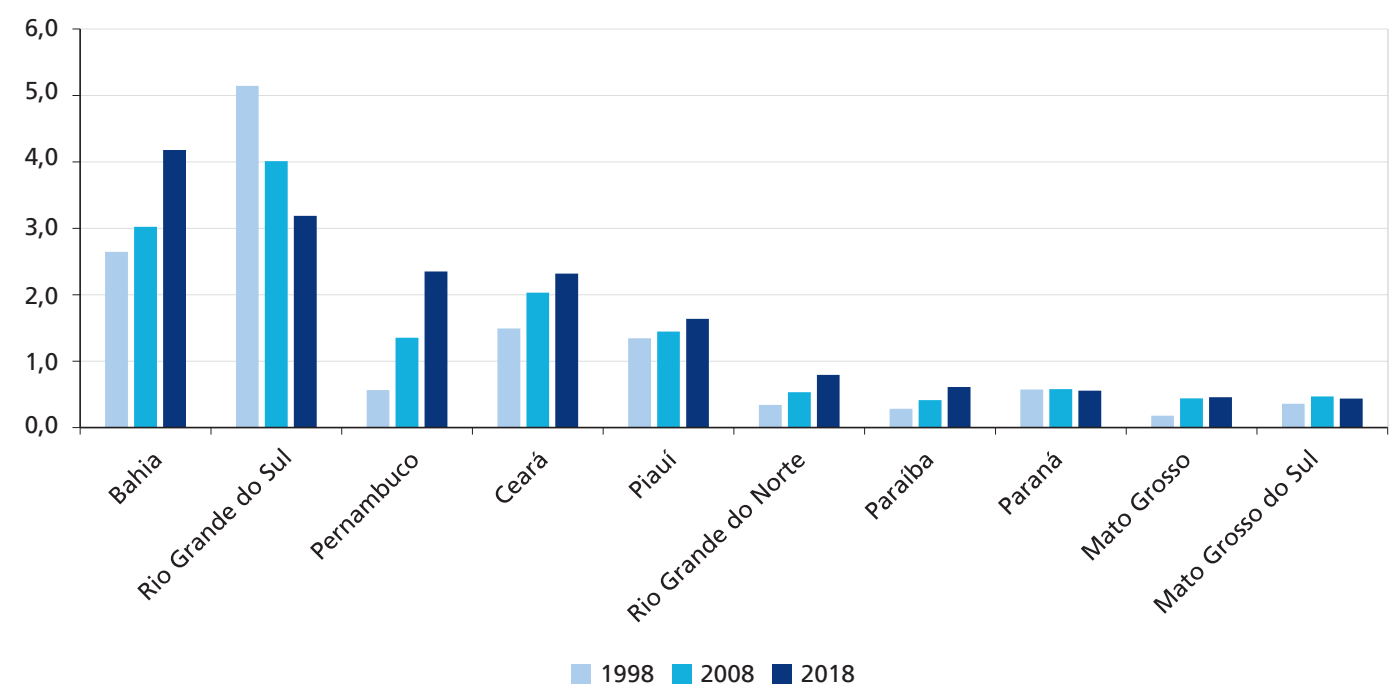

Fonte: IBGE (2018).

Pernambuco também cresceu no número de ovinos criados, contabilizando 2,4 milhôes de cabeças, com cerca de 24 cabeças $/ \mathrm{km}^{2}$, em 2018 . Relacionando com o período de 1998 a 2008 e de 2008 a 2018, esse estado cresceu 316,1\% e 73,8\%, respectivamente. Diferentemente do cenário envolvendo o rebanho de caprinos, em relação ao Piauí, o Ceará vem apresentando ao longo dos anos um maior quantitativo de ovinos - este com 2,3 milhôes de cabeças e uma densidade de dezesseis animais $/ \mathrm{km}^{2}$, e aquele com 1,6 milhóes e seis cabeças $/ \mathrm{km}^{2}$.

Numa análise comparada com a população local, conforme ressalta Andrade (1976), é importante se atentar não apenas para o tamanho do rebanho no respectivo território, mas também para sua proporção em relação à população existente. Seguindo 
essa referência, destaca-se que na criação de caprinos e ovinos, o estado com maior proporção é o Piauí: 0,561 caprinos por habitante e 0,5 ovinos por habitantes. Portanto, assim como argumentam Souza e Barros (2017), esse dado reforça um indicativo de grande importância: a considerável presença de pequenos agricultores familiares na pecuária náo-bovina no Nordeste, especialmente nesse estado, o mais interiorizado da região nordestina e detentor da menor faixa litorânea em relação aos demais. O gráfico 4 ilustra esses comparativos por Unidade da Federação (UFs).

GRÁFICO 4

Número de animais por habitante nos cinco principais estados (2018)

(Em cabeças/habitantes)

$4 \mathrm{~A}-$ Caprinos

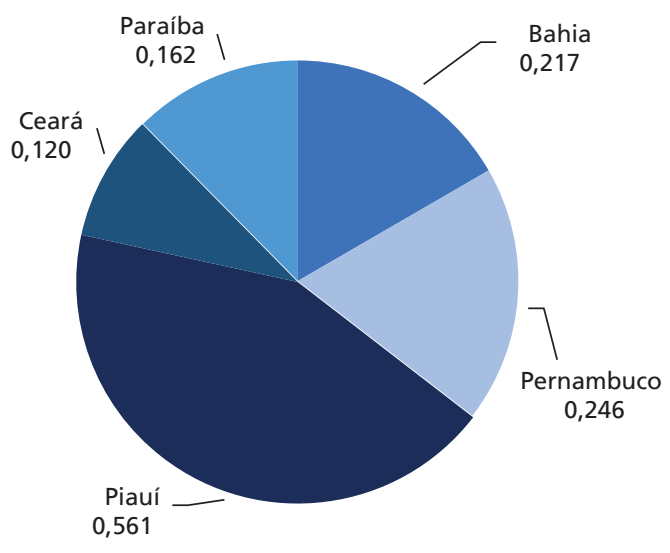

Fonte: IBGE (2019)

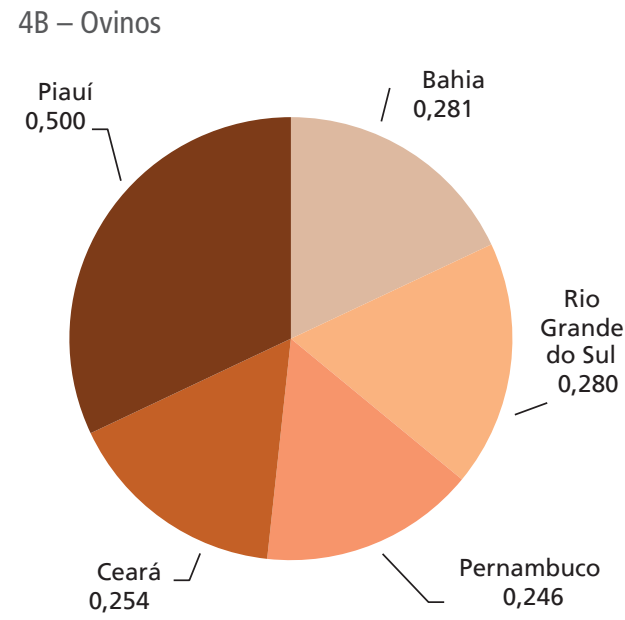

Considerando as análises realizadas, os estados da Bahia, Pernambuco, Piauí e do Ceará se destacam na caprinovinocultura do Nordeste. Souza e Barros (2017) argumentam ser fator importante para a sustentabilidade da população rural nordestina o baixo custo de manutenção da caprinocultura. Segundo a Associação Brasileira de Santa Inês - ABSI (ABSI, 2013), outra questão relacionada ao crescimento da caprinovinocultura nos estados do Nordeste é a maior demanda dos produtos oriundos por parte da população, local ou não, e ao maior apoio governamental e de instituiçôes de referências do setor, além da interrelação entre estes.

Vale destacar a importância desses pequenos estabelecimentos, preponderantemente de agricultura familiar, na criação de caprinos e ovinos, não apenas na região Nordeste. O número de estabelecimentos, conforme IBGE (2017), chega a 236 mil 
com criação de caprinos e 313 mil com ovinos, apresentando, ainda, uma média de 23 caprinos e vinte ovinos por propriedade. Torna-se interessante ainda ver que em outras regióes do Brasil, especialmente a região Sul, conserva-se uma quantidade expressiva de estabelecimentos criando ovinos e caprinos, computando mais de 47,5 mil na criação de ovinos e cerca de 10 mil na de caprinos, com uma média de 22 ovinos e nove caprinos por estabelecimento (gráfico 5).

\section{GRÁFICO 5}

Número de estabelecimentos da agricultura familiar com caprinos e ovinos e média de animais (2017)

(Em unidades)

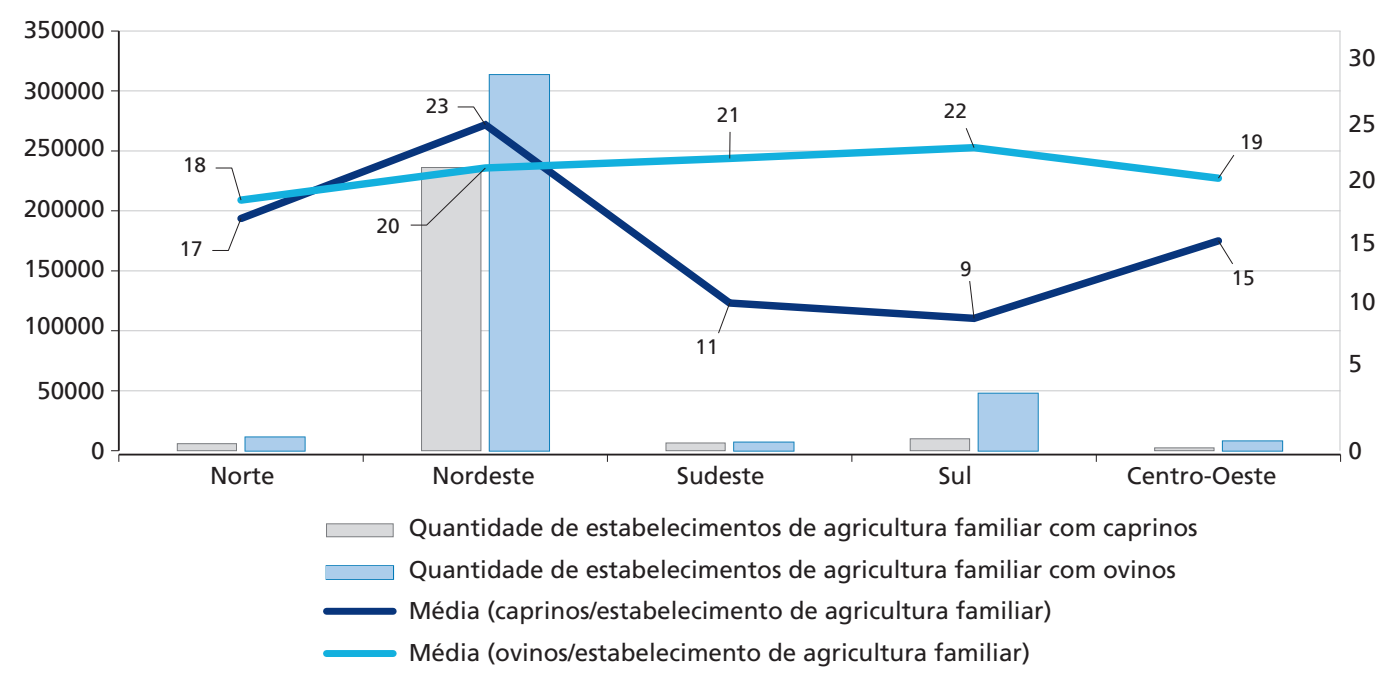

Fonte: IBGE (2017).

Ressaltam-se, portanto, as diversas características positivas à criação desses animais. De maneira geral, caprinos e ovinos são animais que podem apresentar características como a rusticidade, a capacidade de enfrentar climas adversos, a boa adaptabilidade a diferentes ambientes, dentre outras, sem desfavorecer a viabilidade econômica da criação, embora isso não seja uma regra (Gomes et al., 2014).

Nesse sentido, a Embrapa (2016) destaca que a criação desses ruminantes domésticos de médio porte no Brasil tem um elevado potencial, pois, além do que foi pontuado anteriormente, as condiçóes ambientais na maioria das vezes propícias, aliadas à disponibilidade de terras, principalmente aquelas localizadas nas fronteiras em expansão - no semiárido, principalmente - podem favorecer custos produtivos mais baixos, tornando o mercado de animas e produtos derivados mais propício e favorável. 
Conforme observado dentre as regiōes do Brasil, a Nordeste é a que mais se sobressai, e isso está fundamentado tanto pela densidade, quanto pela proporção de animais por habitante, assim como pela quantidade criada de caprinos e ovinos, uma concentração de $93,9 \%$ e $66,7 \%$ do rebanho nacional, respectivamente (gráfico 6).

GRÁFICO 6

Efetivo por região do Brasil (2018)

(Em milhões de cabeças)

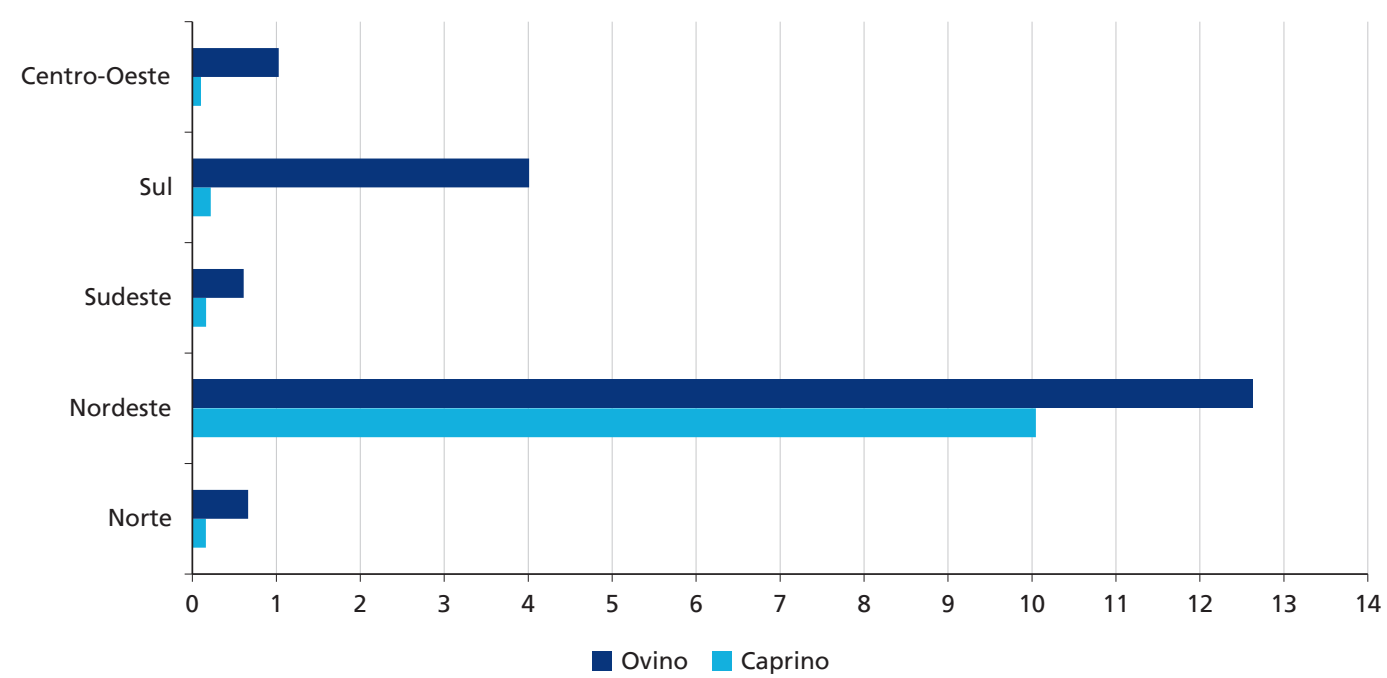

Fonte: IBGE (2018)

Mostra-se evidente que a região Sul tem um rebanho de caprinos bem pequeno e um efetivo considerável de ovinos, atividade tradicional da regiáo, sendo que o efetivo de ambos tem decrescido ao longo do tempo.

Enquanto isso, a regiáo Nordeste desponta na produção desses animais, ainda que não seja uma realidade em grande parte do território (Aquino et al., 2016; Ribeiro e Alencar, 2018). É, portanto, nessa regiáo que se encontra a maior parte do semiárido brasileiro (Correia et al., 2011), assim como o maior número de estabelecimentos da agricultura familiar na atividade pecuária (IBGE, 2017) e um Índice de Desenvolvimento Humano (IDH) bem melhor que há 25 anos (Alves e Vieira Filho, 2019), embora ainda apresente diferentes características físicas e socioeconômicas em seu território. 
Um fato interessante é que, embora a região Sul apresente uma menor quantidade de estabelecimentos da agricultura familiar com criação de animais de médio porte, ${ }^{1}$ com cerca de 81,3 mil estabelecimentos em relação à região Nordeste - que apresenta aproximadamente 390,8 mil -, a Sul ainda sim obteve o valor da produçáo maior, com mais de R \$ 2,59 milhões de reais em 2017, enquanto a Nordeste teve pouco mais que R \$ 977 mil reais, considerando aqueles estabelecimentos com produção no período em que foram levantados os dados do Censo Agropecuário 2017 (IBGE, 2017).

Portanto, é notório o desempenho econômico superior do setor produtivo na regiáo Sul quando comparado com a regiáo Nordeste. Tal destaque coincide com maiores avanços técnicos identificados naquela região, especialmente com a introdução de raças de caprinos e ovinos melhoradas geneticamente e com a inovação de técnicas de manejo específicas, que propiciaram o ganho em produtividade na criaçáo, proporcionando em consequência um melhor desempenho das cadeias produtivas de carnes e couros, especialmente. Essas informaçôes são confirmadas pela Secretaria de Planejamento, Orçamento e Gestão do Rio Grande do Sul - SEPLAG/RS (Seplag, 2019).

Tal realidade fortalece as argumentaçóes de Neves et al. (2004), ao defenderem que uma análise do ambiente externo se torna tâo ou mais relevante que a análise interna das unidades produtivas rurais, seja em relação ao macroambiente (institucional, organizacional e/ou tecnológico) ou ao ambiente imediato (fornecimento, processamento, comércio e mercado).

\section{CADEIA PRODUTIVA DE CAPRINOS E OVINOS}

De um complexo agroindustrial derivam uma série de cadeias. Todavia, há sempre uma cadeia de produção singular (genérica) que simplifica as diversas variaçóes.

Na figura 1 é apresentado um modelo de cadeia produtiva genérica através dos segmentos de produção e fornecimento de insumos, produção primária, processamento e transformação, distribuição e consumo.

1. No Censo Agropecuário 2017, os animais de médio porte são, além dos suínos, os caprinos e ovinos.

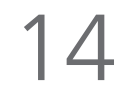


FIGURA 1

Modelo de cadeia produtiva



Financiamento e Tributação

Infraestrutura e Meio Ambiente

Governança e Capital Social

Elaborado pelos autores.

Obs.: Figura cujos leiaute e textos não puderam ser padronizados e revisados em virtude das condições técnicas dos originais (nota do Editorial).

$\mathrm{Na}$ complexidade da configuração de uma cadeia produtiva, os diferentes agentes envolvidos podem atuar de maneira diversa. Os processos permitem a formação de fluxos de bens e serviços a jusante e de capital e informaçóes à montante, num ambiente que pode ter forte influência das estruturas de financiamento e tributação, infraestrutura e meio ambiente, bem como das formas de governança ou coordenação e capital social empregadas ao longo e em diferentes pontos de intersecção da cadeia produtiva.

Desde o século passado, o setor primário dos diferentes setores produtivos da agropecuária passou por importantes transformaçóes, principalmente aquelas relacionadas às mudanças e inovaçôes tecnológicas, sobretudo, relacionadas à modernização dos insumos produtivos (Vieira Filho e Silveira, 2016).

A produção pecuária de ruminantes de médio porte, embora siga a mesma trajetória, conservou menos mudanças em sua forma de criação, principalmente no que toca às práticas e ao elevado custo dos insumos a serem utilizados (Medeiros et al., 2005; Ribeiro e Alencar, 2018), assim como à predominância da atividade como de subsistência em algumas regióes do país (Souza e Barros, 2017).

Esse cenário, contudo, sofre mudanças à medida que a caprinovinocultura ganha notoriedade como atividade de maior importância econômica (Embrapa, 2016). Na cadeia de caprinos e ovinos, destacam-se insumos básicos, os quais envolvem os de açáo direta 
e os de impacto indireto. Os de ação direta relacionam-se com a alimentação, como por exemplo, raçóes, concentrados e suplementos (Guimarães Filho, Silva e Azevedo, 2011; Ribeiro e Alencar, 2018), e aqueles relacionados aos produtos veterinários, como vacinas, vermífugos, ectoparasiticidas etc. (Arbage e Reys, 2009; Codevasf, 2011; Guimarães Filho, Silva e Azevedo, 2011). Já os de impacto indireto relacionam-se aos fertilizantes e defensivos agrícolas, como herbicidas, fungicidas e adubos, por exemplo, para o cultivo de pastagens de qualidade, além de outros volumosos e concentrados destinados à alimentação dos animais, especialmente nos períodos de seca.

No segmento que envolve os produtores/criadores, destacam-se as atividades de cria, recria e engorda; produção de leite, carne, lã e pele; além da produção de alimentos para o rebanho, como silagem, produção de forrageiras para corte, fenação e formação de pastagens, bem como instalaçóes e assistência técnica (Codevasf, 2011).

No mundo, existem diversas raças de caprinos e ovinos, sendo que no Brasil algumas delas se fazem mais presentes do que outras (Sorio, 2017). O motivo disso está na aptidão produtiva dos animais, proporcionada principalmente pelo melhoramento genético animal com foco em atributos funcionais específicos (produção de leite, carne, lã ou pele), na adaptação deles às condiçóes ambientais, assim como na sua rusticidade e rendimento de carcaça (Medeiros et al., 2005). O quadro 1 destaca algumas raças de maior prevalência.

QUADRO 1

Principais raças caprinas e ovinas para produção de carne, leite, lã e pele

\begin{tabular}{|c|c|c|}
\hline Aptidão & Principais raças caprinas & Principais raças ovinas \\
\hline \multirow{6}{*}{ Carne } & \multirow{3}{*}{ Boer } & Somalis \\
\hline & & Dorper \\
\hline & & Texel \\
\hline & \multirow{3}{*}{ Anglo-nubiana } & Hampshire \\
\hline & & Ile de fance \\
\hline & & Suffolk \\
\hline \multirow{3}{*}{ Leite } & Saanen & \multirow{3}{*}{ Lacaune } \\
\hline & Toggenburg & \\
\hline & Alpina & \\
\hline \multirow{2}{*}{ Lã } & - & Texel \\
\hline & - & Suffolk \\
\hline \multirow{3}{*}{ Pele } & SRD & \multirow{3}{*}{$\begin{array}{l}\text { Santa Inês } \\
\text { Morada nova }\end{array}$} \\
\hline & Moxotó & \\
\hline & Anglo-nubiana & \\
\hline
\end{tabular}

Fonte: adaptado de Codevasf (2011). 
Segundo o MIN (Brasil, 2017), a oferta dos produtos da caprinovinocultura no Brasil não é qualificada como se deveria, principalmente quando consideramos a importância do Nordeste nesse segmento. Segundo Alves e Souza (2015), e também detectado já no estudo de Brisola (2011), isso ocorre, de forma especial, devido ao fato de os produtores não serem devidamente remunerados, além de serem pouco capacitados e/ou organizados, não proporcionando uma oferta uniforme e regular durante o ano.

É sabido ainda que grande parte dos produtores náo tem como atividade principal a caprinovinocultura, mas sim atividades como a bovinocultura de corte, o que acaba levando a uma baixa especialização da máo de obra e também à falta de informaçóes adequadas quanto ao desenvolvimento da criação por parte de muitos produtores, independentemente da aptidão do rebanho (Sorio, 2017).

Considerado um fator importante no desenvolvimento da caprinovinocultura, a estrutura de criação tem características específicas e podem apresentar variaçôes, dependendo do território. De forma geral, essa estrutura é composta por instalaçôes e equipamentos, tais como centro de manejo, aprisco, sala de ordenha, instalaçóes específicas para reprodutores, curral de parição, área para isolamento de animais, infraestrutura complementar (comedouros, bebedouros, saleiros, pedilúvios), cercas, esterqueira, depósito de ração e farmácia (Codevasf, 2011).

Não obstante, outro fator importante na criação de caprinos e ovinos são os sistemas produtivos adotados, os quais podem ser classificados como intensivos, semi-intensivo e extensivo (Silva, 2018). Todavia, o autor ainda enfatiza que a maioria dos criadores familiares estâo localizados em diferentes regiôes e utilizam os sistemas de criação semi-intensivo e extensivo, nessa ordem. Diferentemente do que levantaram Medeiros et al. (2005), os quais destacaram a utilização predominante do sistema extensivo no semiárido nordestino, devido principalmente pela escassez de alternativas restritas pelo baixo custo de capital da terra e do trabalho.

Em um dos estudos proporcionados pelo Sistema Nacional de Aprendizagem Rural - Senar (Senar, 2019), mostra-se que o semi-intensivo apresenta melhor desempenho nos índices de produtividade em relação aos demais, principalmente considerando às condiçôes ambientais do país. Destaca-se, portanto, que, em relação ao sistema extensivo, o semi-intensivo favorece um melhor manejo alimentar e sanitário do rebanho. Por sua vez, o sistema extensivo é mais simples, nele os animais são criados a pasto, o custo de produção é baixo, o desempenho dos animais depende das condiçóes climáticas e da fertilidade do solo, sendo que nele, o emprego de tecnologias é mais baixo, o que impacta diretamente a produtividade. 
Independente da finalidade econômica dos animais criados, o ciclo de produção de caprinos e ovinos pode variar de acordo com os objetivos que se querem atingir ou o produto que se pretende ofertar.

Quando o rebanho criado é voltado para a produção de carne, por exemplo, o ciclo é de aproximadamente noventa dias, sendo o produto um cordeiro/cabrito desmamado; se forem animais finalizados para abate, este será de 180 dias; ou, caso se pretenda produzir matrizes e reprodutores, o ciclo será próximo de 270 dias (Martins, 2010). No caso da produção de leite, a duração de lactação varia de 240 a 305 dias, dependendo da raça (Codevasf, 2011), enquanto em relação à lá, os animais geralmente devem ser tosquiados uma vez ao ano, dependendo da raça e do nível de bem-estar que se pretende proporcionar aos animais.

Os principais destinos da carne e do leite de caprinos e ovinos são os abatedouros, frigoríficos e as unidades de beneficiamento (Codevasf, 2011), sendo que nesses segmentos são produzidas linguiças, cortes de carnes frescas, salgadas e secas, queijos, iogurte, dentre outros (Sidersky, 2018). Quanto à pele e lá, o principal destino é a indústria de vestuários e calçados (Gomes et al., 2014; Amarilho-Silveira, Brondani e Lemes, 2015). Não obstante, Sidersky (2018) destaca que ainda existe a possibilidade da exploração econômica de alguns produtos secundários provenientes e derivados desses animais, como as vísceras e similares (língua, fígado, coração e pulmôes), os chifres e o esterco, ademais de uma rica produção classificada como artesanato.

\section{LIMITAÇÕES E AVANÇOS EVIDENCIADOS NAS CADEIAS PRODUTIVAS DA CAPRINOVINOCULTURA NO BRASIL}

Existem muitas açóes que visam reduzir as demandas e ampliar a profissionalização da produção de ovinos e caprinos, bem como dos agentes que integram o complexo agroindustrial da caprinovinocultura e suas cadeias produtivas no Brasil. Especificamente na região Nordeste, por causa dos longos períodos de seca e da carência socioeconômica local, tem-se as açôes públicas. São destacados os seguintes programas e projetos: Dom Helder Câmara II (implementado pelo governo federal); Projeto de Desenvolvimento Sustentável do Cariri, Seridó e Curimataú (Procase), na Paraíba; Viva o Semiárido, no Piauí; Dom Távora, em Sergipe; Paulo Freire, no Ceará; e Pró-Semiárido, na Bahia 
(implementados pelos governos estaduais). Vê-se que as principais políticas públicas de fomento ao desenvolvimento da agricultura familiar nesse setor produtivo estáo sendo implementadas, principalmente, pelos governos estaduais, embora grande parte seja financiada pelo governo federal (Rocha e Dias, 2019):

Partindo do diagnóstico realizado por Brisola (2011), acredita-se que muitos dos problemas evidenciados no setor se conservem até os dias atuais. Desde a produção rural até o consumo de produtos derivados, o retrato que se mostrou nesse diagnóstico (quadro 2) revela uma carência de âmbito institucional, organizacional e inter-relacional, que percorre a atividade rural e chega ao consumo, perpassando a indústria e os sistemas de distribuição. Muitas das demandas são atribuídas às carências de políticas e açóes públicas.

QUADRO 2

Principais problemas identificados no setor da caprinovinocultura

\begin{tabular}{|c|c|}
\hline Tipo de problema & Descrição - por ordem de relevância \\
\hline \multirow{6}{*}{$\begin{array}{l}\text { Relacionados à produção rural e ao perfil do } \\
\text { produtor }\end{array}$} & Descontinuidade e/ou desqualificação da assistência técnica \\
\hline & Baixo estímulo empreendedor e restrita profissionalização do produtor \\
\hline & Mão de obra despreparada e/ou insuficiente para lidar com o manejo adequado dos animais \\
\hline & Baixa rentabilidade da atividade - dificuldades financeiras para implantação de tecnologias \\
\hline & $\begin{array}{l}\text { Doenças e outros problemas relacionados ao manejo de animais, com prejuízo na comercializa- } \\
\text { ção de animais e derivados }\end{array}$ \\
\hline & Falta de incentivo ao melhoramento genético - alto custo dos reprodutores \\
\hline \multirow{3}{*}{$\begin{array}{l}\text { Relacionados à integração e organização das } \\
\text { cadeias derivadas }\end{array}$} & Necessidade de maior integração - papel das câmaras setoriais e redes de negócios \\
\hline & 0 rebanho existente não atende à demanda em quantidade e qualidade \\
\hline & Necessidade de projetos integrados, que formem escala para a comercialização \\
\hline \multirow{10}{*}{$\begin{array}{l}\text { Relacionados às ações do ambiente organizacional } \\
\text { (público e privado) ao longo da cadeia de produção }\end{array}$} & Crédito rural limitado e com alto custo \\
\hline & Falta de informações precisas sobre os números de rebanho \\
\hline & Informalidade no abate \\
\hline & Deficiente regulamentação de mercado \\
\hline & Alta tributação \\
\hline & Falta de tecnologia adaptada à região - carência de pesquisas para o setor \\
\hline & Falta de objetividade nos programas de fomento: elevado custo burocrático \\
\hline & Logística de transporte inadequada e insuficiente \\
\hline & Falta de uma planta frigorífica adequada à demanda (ajustada aos pequenos abates) \\
\hline & Falta de estímulo ao consumo de carne e leite (necessidade de divulgação e criação de eventos) \\
\hline \multirow{3}{*}{$\begin{array}{l}\text { Relacionados às ações do ambiente institucional } \\
\text { (formal e informal) }\end{array}$} & Falta de organização do setor/informalidade nas transações \\
\hline & Reduzido apoio institucional - descontinuidade das políticas públicas \\
\hline & Barreiras culturais ligadas à resistência à adoção de tecnologias \\
\hline
\end{tabular}

Fonte: adaptado de Brisola (2011). 
A informalidade é um dos fatores que muito impacta negativamente a competitividade do produto e o desenvolvimento da cadeia global, visto a consequente ambientação para a desleal concorrência entre produtores e agroindústrias, sendo que Sorio e Rasi (2010) estimaram, há dez anos, que $90 \%$ da carne ovina consumida no país eram provenientes do mercado informal, sendo que poucas medidas foram articuladas para resolução desse problema nos anos seguintes. Os autores ainda argumentam que a informalidade está presente em vários estágios da cadeia - na criação, na comercialização, no abate e no processamento.

Na produção rural, a informalidade surge na forma de ausência de inspeção sanitária no momento do abate, sonegaçáo e falta de comunicação da movimentação de animais aos órgãos pertinentes de defesa sanitária.

Ao que parece, a partir da análise supracitada, muitos dos problemas decorrem da própria estrutura de produção, que tende fortemente à informalidade. Tal informalidade conduz a uma inatividade do setor público e um consequente desinteresse ou incapacidade de reação competitiva do setor privado. Os setores a jusante (processamento, distribuição e comercializaçáo de produtos derivados) sofrem as consequências dessa informalidade, sendo prejudicados com a ausência de escala de produção e qualidade da matéria-prima.

Os agentes envolvidos no processamento têm papel fundamental no desenvolvimento da cadeia, porém, as agroindústrias e processadores de produtos caprinos e ovinos geralmente operam abaixo do ponto de equilíbrio ou aquém da capacidade instalada, e isso acaba dificultando o pagamento por qualidade e comprometendo a competitividade do produto local diante daqueles importados (Brasil, 2017).

Soluçôes para essa situação passam pelo desenvolvimento de novas tecnologias para o estabelecimento e desenvolvimento de abatedouros que operem a baixo custo e em menores escalas, aptos a desenvolverem atividades de desossa e processarem produtos com conformidade legal mínima aceitável por normas voltadas à produção artesanal, respeitando as boas práticas agropecuárias e sanitárias, e se apropriando dos benefícios do selo "arte", que representa uma interessante alternativa. ${ }^{2}$

2. A Lei no 13.680, de 14 de junho de 2018, determina que os produtos sejam submetidos à inspeção dos órgãos sanitários dos estados e do Distrito Federal. 0 produto artesanal será identificado, em todo o país, por um selo único com a indicação "arte". Mais informações em: <https://bit.ly/2RXjPMV>. 
$\mathrm{Na}$ indústria, estágio da cadeia que mais preocupa, por representar elo intermediário entre a produção e o consumo, aloja vários agravantes, tais como a aquisiçáo de animais sem conformidade (doentes) e sem qualidade, ausência de inspeção sanitária durante o abate e transporte inadequado - embalagem e condicionamento do produto de forma inadequada - e finalmente, sonegação de imposto. Já na comercialização, a informalidade refere-se à sonegação ao fisco e aquisição de produtos sem inspeção sanitária dos produtos.

Junto a esses fatores, o não atendimento de legislação específica sobre o abate e a falta de programas de incentivo ao setor influenciam a estrutura de governança assumida pelas agroindústrias, que se baseia na compra do produto no mercado à vista. ${ }^{3}$ Assim, o preço de mercado presente é o que coordena as transaçóes comerciais realizadas. Logo, em geral, os produtores acabam desestimulados a entregarem toda a sua produção aos frigoríficos legalizados (Sorio e Rasi, 2010).

Tais problemas geram a preocupaçáo que leva a crer que políticas públicas especificas, principalmente voltadas à fiscalização e a formas inovadoras de administração das transaçôes comerciais, devem ser articuladas para ajustar esses fatores, assim como a estruturaçáo de fundos de investimentos do setor privado para inovação do sistema produtivo e estratégias comerciais para defesa dos interesses comuns na cadeia, inclusive para a preparação de núcleos específicos direcionados e preparados sanitariamente para o abastecimento interno e externo, e até mesmo para a exportaçáo de animais vivos para mercados consumidores de carne quente.

De acordo com a Federação das Associações Muçulmanas do Brasil - Fambras (Fambras, 2016), o Brasil é um exportador de produtos Halal que demostra um grande potencial de crescimento neste mercado, principalmente considerando o grande potencial de otimização da cadeia de caprinos e ovinos, sendo que, dentre os principais compradores estão a Arábia Saudita, Emirados Árabes, Kuwait e Iraque.

A carne, o leite, a lã e o couro de cabras e ovelhas podem apresentar características diversas, as quais devem ser levadas em consideração para que o valor a ser agregado nessa etapa proporcione ao menos a qualidade necessária exigida por diferentes consumidores, de forma que promova a competitividade do produto em diferentes mercados.

3. Acordo feito no momento entre comprador e vendedor, caracterizado pela entrega imediata e simultânea do dinheiro no momento das ações negociadas, ou seja, a liquidação física e financeira é à vista. 
Ano após ano, observa-se que a demanda por carne de caprinos e ovinos tem sido fortemente influenciada pelos preços relativos do produto e pela renda média dos consumidores (Embrapa, 2018). Todavia, a influência de fatores sociais e culturais também tem sido muito marcante em seu mercado consumidor.

A produção de carne gera atividades e produtos complementares, como é o caso da oferta de peles, tanto de ovinos quanto de caprinos. Embora possa ser considerado como subproduto, a competitividade da recuperação do consumo doméstico de couro em substituição aos materiais sintéticos deverá crescer e, com a elevaçáo da renda e mudanças de hábitos dos consumidores, a valorização destes tendem a aquecer os mercados correlatos. O fato é que a pele de boa qualidade agrega valor na atividade, remunerando melhor os produtores (Embrapa, 2018).

Entretanto, no Tocantins, por exemplo, as peles de caprinos e ovinos acabam sendo jogadas fora pela maioria dos criadores, ignorando a possibilidade de venda deste produto (Sorio, 2017), o que muitas vezes é atribuído à falta de conhecimento dos produtores sobre seu potencial econômico e de mercado. Adiciona-se a isso as questóes tributárias envolvendo o setor, que apresentam características de desequilíbrio, favorecendo a dominância de produtos substitutos oriundos de cadeias mais bem estruturadas e articuladas, especialmente produtos como couros e lãs sintéticas.

Quando exportada, a pele de ovinos e caprinos do Brasil geralmente é comercializada como wet blue e importada com acabamento, embora tal transação possa ser feita com a pele seca também (Brasil, 2017). O fato é que recai aí, também, a demanda por políticas e ações de interesse público-privadas que venham a contribuir para o fortalecimento e sustentabilidade econômica do setor.

Quanto ao leite, a Embrapa (2018) destaca o grande potencial para o mercado de lácteos funcionais, com funçóes probióticas e que detenha alto valor agregado, além da sua capacidade de substituir produtos lácteos de origem bovina, visto que esse produto derivado de caprinos e ovinos serve como alternativa alimentar para pessoas com alergias ou rejeição ao leite de vaca. Apesar de ser um produto alimentício com características nutricionais muito diferenciadas e com elevado potencial de consumo, grande parte desse leite, em algumas regiốes do país, não é destinado ao consumo humano, sendo utilizado principalmente para alimentação de suas crias e de outros animais, em função da baixa 
especialidade e tecnificação da produção. Adequadas estruturas de produção, alinhadas a canais de distribuição eficientes, contribuem para a criação de expectativas de ampliação da renda e fortalecimento da cadeia de lácteos e derivados da caprinovinocultura.

Ainda no que tange à comercialização de produtos derivados, especialmente o leite, é sabido de irregularidades decorrentes da venda aos Programa de Aquisição de Alimentos (PAA), do governo federal - quando, por exemplo, o Cadastro de Pessoas Físicas (CPF) de terceiros é utilizado indevidamente, gerando insustentabilidade do programa, inibindo a estruturação do mercado privado e impossibilitando o melhor entendimento do ambiente real por entidades governamentais devido à falta de dados oficiais e confiáveis.

Assim, se por um lado há tantas questôes que desfavorecem a regularidade da oferta de caprinos e ovinos, prejudicando todo o fluxo de produçáo das cadeias do setor - como os mercados com o elevado preço dos produtos e a baixa oferta, o que consequentemente evidencia a manutenção de um baixo nível de consumo dos seus produtos -, por outro lado, é possível identificar iniciativas e experiências positivas no Brasil, tal como se evidencia no programa identificado como Rota do Cordeiro e em alguns modelos de cooperativas bem estabelecidas, bem como em integraçóes formais e informais concretizadas entre produtores. A reprodução de modelos como estes, direcionados por entidades públicas e privadas, universidades e o próprio sistema ' $S$ ' permitiram a multiplicaçáo de novas realidades mais promissoras.

Pode-se destacar também, como ação positiva ao setor, a Lei de Integração no 13.288, de 2016, apta a ser aplicada ao relacionamento entre produtor e agroindústria como um mecanismo de potencial inclusão de agricultores familiares no fornecimento de produtos lícitos e no estabelecimento de equilíbrio nas negociaçôes entre esses importantes agentes da cadeia produtiva de caprinos e ovinos.

Todavia, a profissionalização e capacitação gerencial dos produtores torna-se algo importante e necessário a potencializar ainda mais esse mecanismo legal, elevando a confiança do real cumprimento dos acordos de fornecimento e outras contrapartidas entre as partes envolvidas. 
Vale destacar que alguns estados produtores de caprinos e ovinos destinam parte de seus produtos e derivados a outros estados brasileiros (Ribeiro e Alencar, 2018), enquanto alguns não possuem nem essa condição, devido aos vários problemas e limitaçôes existentes relacionados à qualidade sanitária dos rebanhos e aos custos alinhados a essa comercialização.

As questóes relacionadas à sanidade animal derivam em muito da deficiência nutricional dos rebanhos, contribuindo para o baixo desempenho produtivo e restringindo-se o abastecimento nos próprios mercados locais (Sorio, 2017).

Oliveira (2008) indica que as questôes sanitárias na criação de caprinos e ovinos estão fortemente ligadas ao manejo na propriedade, enquanto Cruz et al. (2019) enfatizam que a vermifugação e a vacinação contra raiva e clostridioses são consideradas as práticas a serem adotadas pelos criadores de caprinos e ovinos, e nem sempre adotadas. O que se pode perceber é que zoonoses de extrema relevância como brucelose e tuberculose são pouco tratadas ou prevenidas, ou seja, não estão recebendo a devida atenção.

Cruz et al. (2019) argumentam ainda que a falta de implantação de práticas como essas pode ser contornada com a introdução de boas práticas de manejo sanitário pelos agricultores, derivadas de iniciativas mais efetivas por parte da União e das UFs, e até mesmo de fundos privados que promovam o desenvolvimento de açóes voltadas à assistência técnica e à capacitação.

Observando a evolução do rebanho de caprinos e ovinos, suas características e importâncias regionais é possível identificar significativos pontos que requerem alguma intervenção. Ribeiro e Alencar (2018) concordam que o elevado custo de aquisição de insumos alimentícios em algumas regióes do país acaba sendo um dos principais limitantes à produção de caprinos e ovinos de forma adequada e rentável, assim como o MIN (Brasil, 2017) destaca o uso indiscriminado de produtos veterinários pelos criadores. Não obstante, Guimarães Filho, Silva e Azevedo (2011) ressaltam que a utilização restrita de fertilizantes e defensivos nas propriedades rurais, aliada ao manejo inadequado das pastagens, favorece ao mal desempenho dos sistemas produtivos em diferentes regiôes.

Além de fazerem pouco uso de sistemas intensivos de produção e manterem a produção com baixo nível tecnológico (Senar, 2019), muitos produtores também não possuem a capacitação ou a organização necessária para desenvolverem a atividade. Consoante à pouca eficiência, a baixa remuneração do setor impede a aquisição de 
equipamentos e maquinários adequados para o bom desempenho da atividade, tornando a caprinovinocultura, muitas vezes, uma atividade secundária da propriedade. Segundo Aquino et al. (2016), muitos desses criadores não levam em consideração todas as práticas de controle zootécnico e manejo, o que dificulta a profissionalização da atividade.

\section{CONSIDERAÇÕES FINAIS}

Este estudo buscou trazer uma reflexão sobre as principais características, problemas e avanços que se apresentam nas cadeias produtivas de caprinos e ovinos no Brasil.

Verificou-se o quanto os produtores familiares tiveram e conservaram um papel fundamental para a evolução e o desenvolvimento do setor, especialmente nos estados da regiáo Nordeste.

A cadeia foi fortemente afetada pela introdução de materiais sintéticos em substituição ao couro e à lã. Contudo, mudanças de percepçáo dos consumidores, motivadas por açôes públicas e privadas podem sinalizar um fortalecimento das cadeias derivadas.

Observa-se também situação similar nas cadeias de alimentos (carne e leite), onde o potencial de fortalecimento passa por políticas de amparo, controle sanitário dos rebanhos, incentivos à comercialização por redução de tributos, e movimentos de esclarecimento dos consumidores potenciais sobre os atributos da carne e do leite de ovinos e caprinos.

A escassez de recursos hídricos ainda é um fator que também provoca preocupaçôes, visto a sua capacidade de acarretar grandes prejuízos para o setor, levando em conta que a regiáo Nordeste é a principal produtora e a maioria dos criadores de caprinos e ovinos é agricultores com pouco acesso a tecnologias e com baixa capacidade gerencial, reflexo do baixo nível de orientação técnica ainda oferecida a eles.

Não obstante, o elevado custo com insumos, considerados de grande importância para o setor, aliado à baixa remuneração dos agricultores, desfavorece a produção em sistemas mais eficientes e em escalas comerciais. Consequentemente, por parte das unidades de processamento e transformação, isso desfavorece o pagamento por qualidade e compromete a competitividade dos produtos no mercado. 
Por fim, destaca-se que, na busca de capacitar os produtores e especializar a mão de obra, proporcionando uma melhor organização destes, cooperativas, associaçóes e/ ou os sindicatos, bem como a constituição de câmaras setoriais estaduais e municipais se instituem como estratégias importantes para o desenvolvimento da cadeia produtiva.

O estabelecimento de políticas públicas especificas e direcionadas podem favorecer a cadeia produtiva no que tange à diminuição dos custos de produção e à assistência técnica, garantindo a oferta de melhores condiçóes de créditos, além do fomento à demanda e da exportação dos produtos.

Tudo isso aliado a medidas que objetivam reduzir a informalidade na produção, no comércio, no abate, no processamento e na comercialização, por parte dos governos federal, estaduais e municipais, podem desempenhar um papel central na organizaçáo do setor.

\section{REFERÊNCIAS}

ABSI - ASSOCIAÇÃO BRASILEIRA DE SANTA INÊS. Produtores do Ceará apostam na criaçáo de ovinos e caprinos. 2013. Disponível em: <https://bit.ly/3weQnRN>. Acesso em: 5 jul. 2020.

ALVES, E. R. A. A.; VIEIRA FILHO, J. E. R. O que se espera da irrigação no nordeste? In: VIEIRA FILHO, J. E. R. (Org.). Diagnóstico e desafios da agricultura brasileira. Rio de Janeiro: Ipea, p. 259-293, 2019.

ALVES, E.; SOUZA, G. S. Pequenos estabelecimentos também enriquecem? Pedras e tropeços. Revista de Política Agrícola, v. 24, n. 3, p. 7-21, 2015.

AMARILHO-SILVEIRA, F; BRONDANI, W. C.; LEMES, J. S. Lã: características e fatores de produção. Archivos de Zootecnia, v. 64, n. 247, p. 13-24, 2015.

ANDRADE, M. C. Geografia econômica. 5. ed. São Paulo: Atlas, 1976.

AQUINO, R. S. et al. A realidade da caprinocultura e ovinocultura no semiárido brasileiro: um retrato do sertão do Araripe, Pernambuco. Medicina Veterinária e Zootecnia, v. 10, n. 4, p. 271-281, abr. 2016. 
ARBAGE, A. P.; REYS, M. A. Análise de cadeias produtivas. UFSM, 2009. Disponível em: <https://bit.ly/3bhG4UT>. Acesso em: 23 jul. 2020.

BRASIL. Ministério da Integração Nacional. Bases para o plano nacional de desenvolvimento da rota do cordeiro. 2017. Disponível em: <https://bit.ly/3obeHkA>. Acesso em: 23 jul. 2020.

BRISOLA, M. V. Diagnóstico nacional sobre a ovinocaprinocultura - relatório técnico. Brasília: CSOC-Mapa/CNA/Gecomp-UnB, 2011.

CODEVASF - COMPANHIA DE DESENVOLVIMENTO DOS VALES DO SÃO FRANCISCO E DO PARNAÍBA. Manual de criaçáo de caprinos e ovinos. 2011. Disponível em: <https://bit.ly/3eDOZ4W>. Acesso em: 23 jul. 2020.

CORREIA, R. C. et al. A regiáo semiárida brasileira. 2011. Disponível em: <https:// bit.ly/3w2e13y> Acesso em: 23 jul. 2020.

CRUZ, G. R. B. et al. Aspectos sanitários na produção de caprinos e ovinos de produtores familiares no semiárido paraibano. Revista Conexáo, v. 15, n. 2, p. 129-134, maio-ago. 2019.

EMBRAPA - EMPRESA BRASILEIRA DE PESQUISA AGROPECUÁRIA. Sistema de produçáo de caprinos e ovinos de corte para o semiárido brasileiro. 2016. Disponível em: <https://bit.ly/3blgNJx>. Acesso em: 23 jul. 2020.

Análise da PPM 2016: evoluçáo dos rebanhos ovinos e caprinos entre 2007 e 2016. Boletim do Centro de Inteligência e Mercado de Caprinos e Ovinos, Sobral, CE: Embrapa Caprinos e Ovinos, n. 1, out. 2017.

. Produtos de origem caprina e ovina: mercado e potencialidades na regiáo do Semiárido brasileiro. Boletim do Centro de Inteligência e Mercado de Caprinos e Ovinos, Sobral, n. 3, jul. 2018.

FAMBRAS - FEDERAÇÃO DAS ASSOCIAÇÓES MUÇULMANAS DO BRASIL. Mercado Halal no mundo. 2016. Disponível em: <https://www.fambrashalal.com. br/>. Acesso em: 22 nov. 2020. 
FAO - FOOD AND AGRICULTURE ORGANIZATION OF THE UNITED NATIONS. Faostat: Dados. 2018. Disponível em: <http://www.fao.org/faostat/en/\#home>. Acesso em: 23 jul. 2020.

FMI - FUNDO MONETÁRIO INTERNACIONAL. Seis gráficos sobre impulsionar o crescimento no Brasil. Brasília: FMI, 2019. Disponível em: <https://bit.ly/3eDrbhI>. Acesso em: 23 jul. 2020.

GASQUES, J. G. et al. Total fator productivity in Brazilian agriculture. In: FUGLIE, K. O.; WANG, S. L.; BALL, V. E. (Org.). Productivity growth in agriculture: an international perspective. Oxfordshire: CAB International, p. 145-162, 2012.

GOMES, F. D. S. C. M. et al. A Cadeia produtiva da ovinocultura do estado de Mato Grosso do Sul. In: CONGRESSO DA SOCIEDADE BRASILEIRA DE ECONOMIA, ADMINISTRAÇÃO E SOCIOLOGIA RURAL, Goiânia, 2014 Anais... Sober, 2014.

GUIMARÃES FILHO, C.; SOARES, J. G. G.; ARAÚJO, G. G. L. Sistemas de produção de carnes caprina e ovina no semi-árido nordestino. In: SIMPÓSIO INTERNACIONAL SOBRE CAPRINOS E OVINOS DE CORTE, 1., 2000, João Pessoa, Paraíba. Anais... João Pessoa: Emepa-PB, 2000.

GUIMARÃES FILHO, C.; SILVA, P. C. G.; AZEVEDO, S. G. A cadeia produtiva da caprinovinocultura nos municípios do entorno da barragem de Sobradinho. Petrolina: Embrapa, 2011.

IBGE - INSTITUTO BRASILEIRO DE GEOGRAFIA E ESTATÍSTICA. Censo agropecuário 2006: segunda apuração. Rio de Janeiro: IBGE, 2006. Disponível em: <https://bit.ly/3uL29md>. Acesso em: 20 out. 2020.

. Censo agropecuário 2017: resultados definitivos. Rio de Janeiro: Sidra/IBGE, 2017. Disponível em: <https://bit.ly/3tGpBQl>. Acesso em: 19 out. 2020.

. Pesquisa da pecuária municipal - PPM. 2018. Disponível em: <https://bit. ly/3y5RQeK>. Acesso em: 23 jul. 2020. 
Cidades e estados. 2019. Disponível em: <https://bit.ly/2RVdYrO >. Acesso em: 5 jul. 2020.

JANK, M. S.; ZERBINI, A. N.; CLEAVER, I. Competitividade internacional do agronegócio brasileiro, visão estratégica e políticas públicas. In: RODRIGUES, R. (Org.). Agro é paz: análises e propostas para o Brasil alimentar o mundo. Piracicaba: Esalq, p. 31-68, 2018.

MALAFAIA G. C.; BARCELLOS, J. O. J.; AZEVEDO, D. B. Construindo vantagens competitivas para a pecuária de corte do Rio Grande do Sul: o caso de indicaçáo de procedimento de "Carne do Pampa Gaúcho". In: SEMINÁRIOS EM ADMINISTRAÇĀO (SEMEAD), 9., 2006, São Paulo. Anais... São Paulo: Universidade de São Paulo, 2006.

MARTINS, E. C. Custos de produçáo de ovinos e caprinos. 2010. Disponível em: <https://bit.ly/2SQMfZH>. Acesso em: 23 jul. 2020.

MEDEIROS, J. X. et al. Inova Nordeste iniciativas estratégicas para apoiar inovaçóes no Nordeste: Ovinocaprinocultura. Recife: CGEE/FADE/UFPF, 2005.

NEVES, M. F. et al. Metodologias de análise de cadeias agroindustriais: aplicação para citros. Revista Brasileira de Fruticultura, v. 26, n. 3, p. 468-473, dez. 2004.

OLIVEIRA, E. L. Manejo sanitário de caprinos e ovinos. In: ENCONTRO INTERNACIONAL DA PECUÁRIA DA AMAZÓNIA, 1., 2008, Belém, Pará. Anais... Belém: Faepa; Instituto Frutal; Sebrae/PA, 2008.

RIBEIRO, K. A.; ALENCAR, C. M. M. Desenvolvimento territorial e a cadeia produtiva da caprinovinocultura no semiárido baiano: o caso do munícipio de Juazeiro-BA. Revista Baru-Revista Brasileira de Assuntos Regionais e Urbanos, v. 4, n. 1, p. 144179, jan.-jun. 2018.

ROCHA, L. B.; DIAS, R. F. Monitoramento e avaliação de operaçôes de crédito internacional para o desenvolvimento rural: o exemplo do Fida no semiárido brasileiro. In: MATA, D.; FREITAS, R. E.; RESENDE, G. M. (Org.). Avaliaçáo de Políticas Públicas no Brasil: uma análise do semiárido. Brasília: Ipea, p. 223-250, 2019. 
SEPLAG/RS - SECRETARIA DE PLANEJAMENTO, ORÇAMENTO E GESTÃO DO RIO GRANDE DO SUL. O Rio Grande do Sul é o segundo estado com o maior rebanho de ovinos do Brasil. 2019. Disponível em: <https://atlassocioeconomico.rs.gov. br/ovinos>. Acesso em: 6 jul. 2020.

SOUSA FILHO, H. M.; BONFIM, R. M. Oportunidades e desafios para a inserção de pequenos produtores em mercados modernos. In: CAMPOS, S. K.; NAVARRO, Z. (Org.). A pequena produçáo rural e as tendências do desenvolvimento agrário brasileiro: ganhar tempo é possível? Brasília: CGEE, p. 71-100, 2013.

SORIO, A. Diagnóstico da oferta e demanda de ovinos e caprinos para processamento de carne, pele e leite na regiáo central do Tocantins. Tocantins: Triunfal, 2017.

SORIO, A.; RASI, L. Ovinocultura e abate clandestino: um problema fiscal ou uma solução de mercado? Revista de Política Agrícola, Brasília, v. 19, n. 1, p. 71-83, 2010.

SENAR - SISTEMA NACIONAL DE APRENDIZAGEM RURAL. Ovinocultura: criação e manejo de ovinos de corte. Brasília: Senar, 2019.

SIDERSKY, P. R. Sobre a cadeia produtiva da caprinovinocultura no sertão do Piauí: um estudo centrado no território da Chapada do Vale do Itaim (regiáo de Paulistana). Brasília: FIDA; IICA, p. 94, 2018.

SILVA, C. A. Caracterização do sistema de criaçáo de ovinos no assentamento maria bonita - Delmiro Gouveia/AL. 2018. Dissertação (Mestrado em Agroecossistemas) Universidade Federal de Santa Catarina, Florianópolis, 2018.

SOUZA, L. E. S.; BARROS, R. A. A. Territorialidade Econômica da Pecuária em Manuel Correia de Andrade. Economia-Ensaios, Uberlândia, v. 32, n. 1, p. 113-130, jul.-dez. 2017. 
VIEIRA FILHO, J. E. R.; SILVEIRA, J. M. F. J. Competências organizacionais, trajetória tecnológica e aprendizado local na agricultura: o paradoxo de Prebisch. Economia e Sociedade, Campinas, v. 25, n. 3, v. 58, p. 599-630, dez. 2016.

VIEIRA FILHO, J. E. R.; GASQUES, J. G. Introdução. In: VIEIRA FILHO, J. E. R.; GASQUES, J. G. (Org.). Agricultura, Transformaçáo Produtiva e Sustentabilidade. Brasília: Ipea, p. 15-21, 2016. 
Ipea - Instituto de Pesquisa Econômica Aplicada

\title{
EDITORIAL
}

\section{Chefe do Editorial}

Reginaldo da Silva Domingos

\section{Assistentes da Chefia}

Rafael Augusto Ferreira Cardoso

Samuel Elias de Souza

\section{Supervisão}

Camilla de Miranda Mariath Gomes

Everson da Silva Moura

\section{Revisão}

Alice Souza Lopes

Amanda Ramos Marques

Ana Clara Escórcio Xavier

Clícia Silveira Rodrigues

Luiz Gustavo Campos de Araújo Souza

Olavo Mesquita de Carvalho

Regina Marta de Aguiar

Hellen Pereira de Oliveira Fonseca (estagiária)

Ingrid Verena Sampaio Cerqueira Sodré (estagiária)

\section{Editoração}

Aeromilson Trajano de Mesquita

Anderson Silva Reis

Cristiano Ferreira de Araújo

Danielle de Oliveira Ayres

Danilo Leite de Macedo Tavares

Jeovah Herculano Szervinsk Junior

Leonardo Hideki Higa

\section{Capa}

Danielle de Oliveira Ayres

Flaviane Dias de Sant'ana

\section{Projeto Gráfico}

Renato Rodrigues Bueno

The manuscripts in languages other than Portuguese published herein have not been proofread.

\author{
Livraria Ipea \\ SBS - Quadra 1 - Bloco J - Ed. BNDES, Térreo \\ 70076-900 - Brasília - DF \\ Tel.: (61) 2026-5336 \\ Correio eletrônico: livraria@ipea.gov.br
}



Composto em adobe garamond pro 12/16 (texto) Frutiger 67 bold condensed (títulos, gráficos e tabelas) Brasilia-DF 



\section{Missão do Ipea}

Aprimorar as políticas públicas essenciais ao desenvolvimento brasileiro por meio da produção e disseminação de conhecimentos e da assessoria ao Estado nas suas decisões estratégicas.

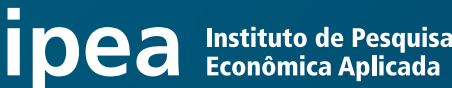 \\ MINISTÉRIO DA \\ ECONOMIA

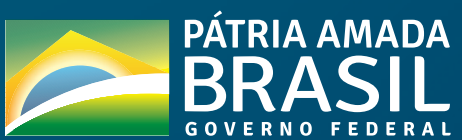

